\title{
Self-stigma among caregivers of people with mental illness: toward caregivers' empowerment
}

This article was published in the following Dove Press journal:

Journal of Multidisciplinary Healthcare

15 January 2014

Number of times this article has been viewed

\author{
Eshetu Girma ${ }^{1,2}$ \\ Anne Maria Möller- \\ Leimkühler ${ }^{2,3}$ \\ Sandra Dehning ${ }^{2,3}$ \\ Norbert Mueller ${ }^{2,3}$ \\ Markos Tesfaye ${ }^{4}$ \\ Guenter Froeschl',5 \\ 'Department of Health Education \\ and Behavioral Sciences, Jimma \\ University, Jimma, Ethiopia; ${ }^{2} \mathrm{CIH}^{\mathrm{LMU}}$ \\ Center for International Health, \\ Ludwig-Maximilians-Universität, \\ Munich, Germany; ${ }^{3}$ Department of \\ Psychiatry and Psychotherapy, Ludwig- \\ Maximilians-Universität, Munich, \\ Germany; ${ }^{4}$ Department of Psychiatry, \\ Jimma University, Jimma, Ethiopia; \\ ${ }^{5}$ Department of Infectious Diseases \\ and Tropical Medicine, Ludwig- \\ Maximilians-Universität, Munich, \\ Germany
}

Background: In addition to economic and material burdens, caregivers of people with mental illness are exposed to psychosocial challenges. Self-stigma is among the psychological challenges that can be exacerbated by intrinsic and/or extrinsic factors. Caregivers' self-stigma can negatively influence the patients' treatment and rehabilitation process. The objective of this study was to measure the level and correlates of self-stigma among caregivers of people with mental illness.

Methods: An interviewer-administered cross-sectional study was conducted in the Jimma University Specialized Hospital Psychiatry Clinic in Ethiopia on a sample of 422 caregivers. Data were collected by trained nurses working in the clinic using a pretested questionnaire. Multivariate linear regression was performed to identify the correlates of self-stigma among caregivers of people with mental illness.

Results: The majority (70.38\%) of the caregivers were male. On a scale of 0 to 15 , with 0 being low and 15 being high, the average self-stigmatizing attitude score was $4.68( \pm 4.11)$. A statistically significant difference in mean self-stigma score was found between urban and rural respondents $(t=3.95, P<0.05)$. Self-stigma of caregivers showed significant positive correlation with perceived signs of mental illness $(r=0.18, P<0.001)$, perceived supernatural explanations of mental illness $(r=0.26, P<0.001)$, and perceived psychosocial and biological explanations of mental illness $(r=0.12, P<0.01)$. The only independent predictor of caregivers' self-stigma was perceived supernatural explanation of mental illness (standardized $\beta=0.22, P<0.001$ ).

Conclusion: The tendency of caregivers to avoid being identified with the patients was observed. Low exposure to mental health information was also reported. Caregivers' self-stigma in this study was significantly correlated with perceived supernatural explanation of mental illness. Since caregivers' self-stigma may negatively influence patients' treatment-seeking, adherence, and rehabilitation processes, programs that enhance coping strategies by strengthening selfesteem and empowerment by health care providers and establish family support groups may be helpful to tackle self-stigma among caregivers of people with mental illness.

Keywords: self-stigma, internalized stigma, caregivers, mental illness

\section{Introduction}

Care and support from caregivers during periods of illness are critical for people with mental illness. Care from family members or friends is especially important in resourcepoor settings like Ethiopia, where family and friends are considered to be "frontline caregivers". ${ }^{1}$ In addition, families perceive that they have a significant role in coping with the mental illness of the patient. ${ }^{2}$ Recommendations were released in the 1980 s on the importance of considering caregivers as part of the health care system, especially for chronic health problems like mental illness that need long-term care and support., ${ }^{3,4}$
Correspondence: Eshetu Girma Department of Health Education and Behavioral Sciences, Jimma University, PO Box 5093, Jimma, Ethiopia

Tel +25I 910818859

Email grm_sht@yahoo.com 
In the process of seeking help and treatment for patients with mental illness, family members or caregivers often bear economic and material burdens. ${ }^{5-8}$ They are also exposed to psychosocial burdens..$^{5-8}$ Stigma is one of the most challenging psychosocial burdens faced by family members or caregivers of people with mental illness. . $^{2,3,6,8}$

Evidence from around the world shows that the psychosocial burden on family members of people with mental illness negatively affects both family members and the patients that they are caring for. ${ }^{2,9-15}$ One study in the United States found that $43 \%$ of caregivers of people with mental illness believed that most people stigmatize family members of people with mental illness. ${ }^{16}$ Another study on family members of patients suffering from schizophrenia in Morocco reported high levels of perceived stigma and burden on their family members. ${ }^{17}$ The consequences of caregivers' stigma can be more severe if the family or caregivers endorse or accept it (ie, self-stigma). Self-stigma occurs "when individuals belonging to a stigmatized group internalize public prejudice and direct it towards themselves". ${ }^{18}$ Self-stigma is usually aggravated by social stigma and discrimination. ${ }^{19}$

There has been less emphasis on the role of family members or caregivers of the mentally ill in the fight against mental illness stigma. ${ }^{2}$ In particular, evidence on family member/caregiver self-stigma is limited to specific mental illnesses. In the current study, caregivers other than family members were included since previous studies suggest that people have stigmatizing attitudes toward anyone who has contact with the stigmatized person. ${ }^{9,20,21}$

In Ethiopia, where people have diverse explanations of mental illness, complex pathways may cause significant delays to treatment-seeking for mental illness ${ }^{22-24}$ and family members or caregivers may have higher self-stigma. For example, Shibre et $\mathrm{al}^{25}$ revealed that in Ethiopia $75 \%$ of family members of people with mental illness reported some sort of perceived stigma from others due to their mentally ill family member. No other previous studies were found on caregivers' self-stigma in the southwestern part of Ethiopia. Therefore, the current study is the first of its kind in southwestern Ethiopia to exclusively focus on caregivers' self-stigma and its correlates.

\section{Methods}

This institution-based cross-sectional study was conducted among caregivers of people with mental illness at Jimma University Specialized Hospital (JUSH) from June to August 2012. The university hospital is located about $352 \mathrm{~km}$ southwest of the capital city of Addis Ababa. The hospital provides a wide range of clinical services to a population of 15 million. Patients usually come with their caregivers for inpatient services. Most of the caregivers of patients attending for psychiatric services are family members, relatives, or other non-relatives. The study was therefore conducted among attendants who are caregivers of people with mental illness in the JUSH psychiatry facility.

A total of 422 caregivers of people with mental illness were included in the sample. The sample size was estimated using the single population proportion formula. The parameters used to estimate the sample size included a proportion of caregivers with self-stigma of 0.5 to get the maximum representative sample size, since there were no previous studies in the area, and a 95\% confidence level at a 5\% margin of error and $10 \%$ nonresponse rate. Caregivers of both outpatient and inpatient service users were included in the study. Whenever a patient had more than one caregiver, only the primary or main caregiver was included in the study. Only caregivers whose ages were above 18 years were included in the study.

Trained nurses working in the psychiatry clinic collected the data using an interviewer-administered pretested questionnaire adopted from the World Health Organization Family Interview Schedule stigma items (with Cronbach's alpha $=0.85$ ) and other literature..$^{3,26,27}$ Prior to data collection, training was given to data collectors and supervisors in the clinic. A total of 15 items was used to measure self-stigma in caregivers of people with mental illness. The scale included items related to the need to hide the patients' mental illness status (keep secret), feeling of shame (embarrassment), and avoidance of social gatherings and friendships. The items were administered on a "yes $=1$ " or "no $=0$ " basis. A total score of caregivers' self-stigma was computed by summing up the individual items. A higher score therefore indicated higher self-stigma. In addition to the caregiver self-stigma score, sociodemographic and psychographic characteristics related to mental illness such as perceived explanations (supernatural, psychosocial, and biological) and signs of mental illness were measured. Perceived supernatural explanations (three items), psychosocial and biological explanations (six items), and perceived signs of mental illness (12 items) were measured by "yes $=1$ " or "no $=0$ " responses. The sum of items for each variable was then computed so that a higher score indicated higher values for the respective variables.

The tool was translated to Affan Oromo and Amharic languages and back-translated to English to ensure semantic equivalence. After the pretest, some items were modified and additional instruction was given to the data collectors on 
items that were difficult to understand or risked ambiguity. The questionnaire was administered in Affan Oromo or Amharic languages.

Completeness of each questionnaire was checked before data entry. Data was entered into EPI-DATA version 3.1 (The EpiData Association, Odense, Denmark) and exported to STATA version 10.0 (StataCorp LP, College Station, TX, USA) for analysis. Sociodemographic and psychographic variables were analyzed using frequency tables. Correlation, analysis of variance, and $t$-tests were performed to determine the mean difference in caregivers' self-stigma between groups using different sociodemographic and psychographic variables. Multivariate linear regression analysis was performed using variables that had a significant statistical association $(P<0.05)$ in the bivariate analysis. The results of the multivariate analysis were presented using unadjusted and adjusted standardized regression coefficients. The presence of multicollinearity was also checked. Ethical approval was obtained from the Jimma University Research Ethics Review Board. Written permission was obtained from the JUSH clinical director and the psychiatry clinic. Written informed consent was also obtained from each study participant.

\section{Results}

\section{Sociodemographic characteristics}

A total of 422 caregivers of people with mental illness were interviewed for the study with a response rate of $100 \%$. Among them, $70.38 \%$ were male and $67.77 \%$ were married. The mean age of the caregivers was $37.8( \pm 13.9)$ years. Two hundred sixty-six (63.03\%) were Muslims and $61.37 \%$ were members of the Oromo ethnic group. Only $15.40 \%$ of the caregivers were illiterate. Farming and government employment were the leading occupations among the respondents. The proportion of caregivers residing in urban versus rural settings was similar. The majority of the caregivers were either parents $(25.12 \%)$ or other relatives $(25.59 \%)$ of the patients and most of them (81.04\%) were living together with the patients in the same household. The total mean number of years lived with the patients was $18.4( \pm 9.3)$ years and the mean family monthly income was approximately $89.0( \pm 139.0)$ USD (Table 1).

\section{Awareness and perception about mental illness}

As shown in Table 2, only a small proportion of caregivers were exposed to mental illness information on television, the radio, or in religious places. In addition to the patients who they were taking care of during the time of the interview, $16.82 \%$ of the caregivers had had another family member
Table I Background characteristics of caregivers of people with mental illness in Jimma University Specialized Hospital, southwest Ethiopia, 2012

\begin{tabular}{|c|c|c|}
\hline Characteristic & Frequency & Percent \\
\hline \multicolumn{3}{|l|}{$\overline{\text { Sex }}$} \\
\hline Male & 297 & 70.38 \\
\hline Female & 125 & 29.62 \\
\hline \multicolumn{3}{|l|}{ Marital status } \\
\hline Single & 105 & 24.88 \\
\hline Married & 286 & 67.77 \\
\hline Divorced & 14 & 3.32 \\
\hline Widowed & 17 & 4.03 \\
\hline \multicolumn{3}{|l|}{ Religion } \\
\hline Muslim & 266 & 63.03 \\
\hline Orthodox & 104 & 24.64 \\
\hline Other (Protestant, Catholic) & 52 & 12.33 \\
\hline \multicolumn{3}{|l|}{ Ethnicity } \\
\hline Oromo & 259 & 61.37 \\
\hline Amhara & 66 & 15.64 \\
\hline Other (Keffa, Dawro, Gurage) & 97 & 22.99 \\
\hline \multicolumn{3}{|l|}{ Educational status } \\
\hline Could not read and write & 65 & 15.40 \\
\hline Read and write only & 55 & 13.03 \\
\hline Elementary & 112 & 26.54 \\
\hline Secondary & 127 & 30.09 \\
\hline Higher education & 63 & 14.93 \\
\hline \multicolumn{3}{|l|}{ Occupation } \\
\hline Farmer & 153 & 36.26 \\
\hline Government employee & 86 & 20.38 \\
\hline Private enterprise & 79 & 18.72 \\
\hline Housewife & 57 & $|3.5|$ \\
\hline Student & 34 & 8.06 \\
\hline Other (house maid and unemployed) & 13 & 3.08 \\
\hline \multicolumn{3}{|l|}{ Setting } \\
\hline Rural & 213 & 50.47 \\
\hline Urban & 209 & 49.53 \\
\hline \multicolumn{3}{|l|}{ Relationship with the patients } \\
\hline Parent & 106 & 25.12 \\
\hline Son/daughter & 78 & 18.48 \\
\hline Brother & 55 & 13.03 \\
\hline Spouse & 51 & 12.09 \\
\hline Sister & 18 & 4.27 \\
\hline Other relative & 108 & 25.59 \\
\hline Non-relative & 6 & 1.42 \\
\hline \multicolumn{3}{|l|}{$\begin{array}{l}\text { Living together with the patient in the } \\
\text { same household }\end{array}$} \\
\hline Yes & 342 & 81.04 \\
\hline No & 80 & 18.96 \\
\hline
\end{tabular}

with mental illness. Stress $(80.09 \%)$, rumination (68.01\%), and drug addiction (42.18\%) were the most common reported perceived causes of mental illness, while talking to oneself (68.25\%), sleep disturbance (69.19\%), and strange behaviors (63.27\%) were the most common perceived signs of mental illness. The majority of the caregivers $(97.63 \%)$ perceived that mental illness can be cured medically. 
Table 2 Awareness and beliefs about mental illness among caregivers of people with mental illness in Jimma University Specialized Hospital, southwest Ethiopia, 2012

\begin{tabular}{lll}
\hline Variable & Number & Percent \\
\hline Exposure to mental illness information & & \\
Watched on TV & 94 & 22.27 \\
Heard on radio & 99 & 23.46 \\
Religious places & 14 & 3.32 \\
Other family member mentally ill & 71 & 16.82 \\
Perceived cause of mental illness & & \\
Stress & 338 & 80.09 \\
Rumination & 287 & 68.01 \\
Drug addiction & 178 & 42.18 \\
Poverty & 95 & 22.51 \\
God's punishment & 68 & 16.11 \\
Evil spirit & 66 & 15.64 \\
Sinful act & 26 & 6.16 \\
Physical illness & 24 & 5.69 \\
Germs & 5 & 1.18 \\
Other & 16 & 3.79 \\
Perceived signs of mental illness & & \\
Sleep disturbance & 292 & 69.19 \\
Talking to oneself & 288 & 68.25 \\
Strange behavior & 267 & 63.27 \\
Aggression & 186 & 44.08 \\
Talking too much & 185 & 43.84 \\
Restlessness & 179 & 42.42 \\
Self-neglect & 140 & 33.18 \\
Suicidal attempt & 139 & 32.94 \\
Unable to learn & 35 & 8.29 \\
Shivering & 33 & 7.82 \\
Drug addiction & 29 & 6.87 \\
Other & 18 & 4.27 \\
Mental illness can be cured (yes) & 412 & 97.63 \\
\hline
\end{tabular}

\section{Caregivers' self-stigma}

As depicted in Table 3, 163 (38.63\%) caregivers were worried that other people would discover the patients' mental illness and $36.26 \%$ felt the need to hide the patients' illness and also kept the patients' illness secret. In addition, $36.26 \%$ avoided going to social events with the patients. Similarly, $36.97 \%$ felt shame or embarrassment about the patients' illness. One hundred and eleven respondents $(26.30 \%)$ felt that most people blame parents for the mental illness of their children, though only $65(15.40 \%)$ felt that parents of people with mental illness are less responsible and caring than family/relatives without mental illness. Over one in ten caregivers avoided being a member of social events because they had family/relatives with mental illness.

On average, caregivers had a self-stigmatizing attitude on $4.68( \pm 4.11)$ out of the 15 total items. Statistically significant self-stigma differences were obtained between urban and rural respondents $(t=3.95, P<0.05)$. Self-stigma of caregivers also showed significant positive correlation with perceived
Table 3 Frequency distribution of items of self-stigma among caregivers of people with mental illness in Jimma University Specialized Hospital, southwest Ethiopia, 2012

\begin{tabular}{|c|c|c|}
\hline Item & $\begin{array}{l}\text { Yes } \\
\text { N (\%) }\end{array}$ & $\begin{array}{l}\text { No } \\
\text { N (\%) }\end{array}$ \\
\hline $\begin{array}{l}\text { You worried whether people would find } \\
\text { out about (NAME)'s condition? }\end{array}$ & $163(38.63)$ & $259(61.37)$ \\
\hline $\begin{array}{l}\text { You worried that your neighbors } \\
\text { would treat you differently? }\end{array}$ & $148(35.07)$ & $274(64.93)$ \\
\hline $\begin{array}{l}\text { You sometimes felt the need } \\
\text { to hide (NAME)'s illness? }\end{array}$ & I53 (36.26) & $269(63.74)$ \\
\hline You kept (his/her) illness a secret? & I53 (36.26) & $269(63.74)$ \\
\hline $\begin{array}{l}\text { You worried that friends and neighbors } \\
\text { would avoid you after they found } \\
\text { out about it? }\end{array}$ & $125(29.62)$ & $297(70.38)$ \\
\hline $\begin{array}{l}\text { You didn't see some of your friends } \\
\text { as often as you did before? }\end{array}$ & $99(23.46)$ & $323(76.54)$ \\
\hline $\begin{array}{l}\text { You avoided going to large social events } \\
\text { with (NAME)? }\end{array}$ & $153(36.26)$ & $269(63.74)$ \\
\hline $\begin{array}{l}\text { You worried that even your best friends } \\
\text { would treat you differently? }\end{array}$ & $112(26.54)$ & $310(73.46)$ \\
\hline $\begin{array}{l}\text { You felt ashamed or embarrassed } \\
\text { about (NAME)'s illness? }\end{array}$ & $156(36.97)$ & $266(63.03)$ \\
\hline $\begin{array}{l}\text { Have you avoided making friends } \\
\text { because you have a relative who } \\
\text { is mentally ill living with you? }\end{array}$ & $65(15.40)$ & $357(84.60)$ \\
\hline $\begin{array}{l}\text { Do you feel that you are less responsible } \\
\text { and caring than family/relatives without } \\
\text { mental illness? }\end{array}$ & $70(16.59)$ & $352(83.4 I)$ \\
\hline $\begin{array}{l}\text { Do you feel that most people look } \\
\text { down on you since you have a family } \\
\text { member who is mentally ill? }\end{array}$ & II 3 (26.78) & $309(73.22)$ \\
\hline $\begin{array}{l}\text { Do you feel that most people treat families } \\
\text { with a member who is mentally ill in the } \\
\text { same way they treat other families? }\end{array}$ & $113(26.78)$ & $309(73.22)$ \\
\hline $\begin{array}{l}\text { You worried that most people blame parents } \\
\text { for the mental illness of their children? }\end{array}$ & III (26.30) & $311(73.70)$ \\
\hline $\begin{array}{l}\text { Have you ever avoided being a member } \\
\text { of a social gathering because you have } \\
\text { a family member with mental illness? }\end{array}$ & $46(10.90)$ & $376(89.10)$ \\
\hline
\end{tabular}

signs of mental illness $(r=0.18, P<0.001)$, perceived supernatural explanations of mental illness $(r=0.26, P<0.001)$, and perceived psychosocial and biological explanations of mental illness $(r=0.12, P<0.01)$.

\section{Predictors of caregivers' self-stigma}

Variables that were found to have significant statistical associations in the bivariate analysis with self-stigma were entered into a multivariate linear regression analysis. Based on the analysis, place of residence, perceived signs of mental illness score, and perceived psychosocial and biological explanations of mental illness scores did not show significant statistical association with self-stigma. As shown in Table 4, the only variable which showed significant association in the 
Table 4 Multivariate linear regression on the predictors of selfstigma among caregivers of people with mental illness in Jimma University Specialized Hospital, southwest Ethiopia, 2012

\begin{tabular}{lll}
\hline Variable & $\begin{array}{l}\text { Unadjusted } \beta \\
\text { (standardized) }\end{array}$ & $\begin{array}{l}\text { Adjusted } \beta \\
\text { (standardized) }\end{array}$ \\
\hline Urban & $-0.10^{*}$ & -0.07 \\
Perceived signs of mental illness & $0.18^{* * *}$ & 0.11 \\
$\begin{array}{l}\text { Perceived supernatural } \\
\text { explanation of mental illness }\end{array}$ & $0.26 * * *$ & $0.22^{* * *}$ \\
$\begin{array}{l}\text { Perceived psychosocial } \\
\text { and biological explanation } \\
\text { of mental illness }\end{array}$ & $0.12^{* *}$ & 0.06 \\
\hline $\begin{array}{l}\text { Notes: } * P<0.05 * * * P<0.01 * * * P<0.001 . \\
\end{array}$ & \\
\end{tabular}

final model was the perceived supernatural explanation of mental illness score; ie, caregivers with higher supernatural explanations of mental illness had significantly higher self-stigma (standardized $\beta=0.22, P<0.001$ ) (Table 4). Significant interaction was not found between any of the variables to influence self-stigma. This model explained $9.20 \%$ of the variance of self-stigma among caregivers of people with mental illness.

\section{Discussion}

Considering the time gap between the current study and a study conducted 10 years earlier in Southern Ethiopia, ${ }^{25}$ caregiver stigma in the current study was higher. Despite the differences between the two studies, the level of caregiver self-stigma was lower. For example, the mean caregiver self-stigma score was lower than the scale's mean score. Lower levels of self-stigma may be due to lower levels of social stigma of caregivers in the community as the latter usually influences self-stigma. ${ }^{19}$ It may also be the case that caregiving is more equally distributed among several family members, so that the burden of care and self-stigma is not as high in the study community.

Similar to a study conducted in Southern Ethiopia, ${ }^{25}$ the caregivers' self-stigma score was not significantly associated with sociodemographic background of the respondents (sex, religion, relationship to the patients, income, etc). Unlike the current study, age of the caregivers was positively correlated with self-stigma in another study. ${ }^{26}$ In a study in the People's Republic of China, ${ }^{26}$ the duration of stay of the patients was not correlated with self-stigma, which can be related to interventions that empower caregivers to cope with self-stigma and other psychological burdens associated with mental illness. On the other hand, more contact and exposure to people with mental illness reduces stigma of the patients ${ }^{28,29}$ which can also reduce self-stigma among caregivers.
The only variable in the multivariate analysis which was significantly and independently correlated with self-stigma was perceived supernatural explanation of mental illness. Higher perceived supernatural explanation of mental illness was correlated with a higher self-stigma score among caregivers of people with mental illness. The nature of the supernatural explanations, how such explanations were presented, and who should be responsible for the relatives' mental illness can contribute to self-stigma development among caregivers who had supernatural explanations. Future investigations may be helpful to identify the mechanisms of this explanation and how they can influence self-stigma among caregivers. Studies have reported that psychosocial, supernatural, or biological explanations of mental illness can determine the stigma associated with mental illness. ${ }^{28,29}$

Caregivers were concerned about not disclosing the patients' mental illness and being ashamed or embarrassed by it. The caregivers who reported to have avoided social gatherings mostly avoided being seen with the patient at social events. This may be because being seen with the patient might put the caregivers at risk of discrimination by other people. For example, in the current study, a higher proportion of caregivers worried that "most people blame parents for the mental illness of their children" than in a previous report on perceived family stigma. ${ }^{25}$ Similar figures were also obtained for the other items of caregivers' self-stigma, but a decade time gap between the two studies indicates that self-stigma in caregivers is not decreasing.

The sex composition showed that the majority of the caregivers in this study were males. Since the psychiatric facility is situated in an urban area, this could be a result of distance and transport barriers to the facility as there were $20.54 \%$ more males of rural origin than urban origin and this was a statistically significant difference. Females may also be engaged in other household activities and therefore unable to leave the house. In addition, to handle aggressive cases of mental illness, males may be preferable to accompany patients to the hospital. As a result, there may be a high selection bias since male respondents may not be key caregivers of the patients (ie, for each patient, the person who was most responsible among his/her company present in the hospital were included in the sample). On the other hand, whether caregiving for mental illness is associated with sex roles can be a possible area for further community-based exploratory studies since a review report indicated that women are more often primary caregivers than men. ${ }^{30} \mathrm{~A}$ study in the People's Republic of China also showed a higher proportion of female caregivers than male. ${ }^{26}$ 
The majority of the respondents had low exposure to mental health information. For example, $63.74 \%$ of the caregivers were not exposed to such information on any of the three media (radio, television, or in religious places) during the last year. Lower message reach could be related to 1) different media habits of the audiences, 2) recall bias, 3) shortage of mental health communication interventions, or 4) the quality of the mental health communication interventions that do exist.

Though media exposure to mental illness information was low, psychosocial explanations of mental illness prevailed in this study. This may be associated with mental health information at health institutions, since about $17 \%$ of respondents had had family members other than the current patient who were perceived to have mental illness. In addition, the majority of the caregivers (63.03\%) were Muslim, and could have more psychosocial and biological explanations of mental illness. A report suggested that Muslim religion followers had less stigma and more non-supernatural explanation ${ }^{25}$ of mental illness in general, although no statistically significant difference in supernatural explanation score between Muslims and other religions was found in this study. On the contrary, a recent finding reported that Muslim religion followers have more supernatural explanations of mental illness. ${ }^{18}$ However, no other previous studies have reported an association between religion and caregivers' self-stigma.

Visible perceived signs of mental illness such as sleep disturbance, talking to oneself and strange behavior were reported among the caregivers. This could be related to the personal experiences (more than $80 \%$ live together with the patients) and general mental health literacy of the caregivers. In addition, almost all respondents (about 98\%) believed that mental illness is curable by biomedicine. This could be attributed to experiences and beliefs about ethnomedicine, unrealistic expectations caused by biomedicine, and/or social desirability bias since the study was conducted by nurses working in the hospital.

Possible limitations of the present study include study design with limited causal reference, and selection and social desirability biases. In addition, since the sample was taken from hospital attendants, the findings may not represent the primary caregivers, who may have stayed at home or in the community or other traditional treatment places. The variance explaining caregivers' self-stigma may be increased by using more valid constructs and dimensions of caregiver self-stigma measures by conducting qualitative studies with the target groups.

\section{Conclusion}

The overall self-stigma score among caregivers of people with mental illness in this study was low. However, many caregivers avoided being identified with the patients that they care for, which could be associated with fear of stigma from the public. There was low exposure to mental health information through the most popular mass media communication channels, which raises questions about habits of media consumption of caregivers or mental health program availability. Caregivers with high supernatural explanations of mental illness had high selfstigma, which evidences the need to challenge supernatural explanations of mental illness. Since caregivers' self-stigma can negatively affect patients' treatment-seeking, adherence, and rehabilitation process, programs giving caregivers counseling by health care providers and establishing family support groups may be helpful to tackle self-stigma among caregivers of people with mental illness.

\section{Acknowledgments}

We are thankful for the support from the Department of Health Education and Behavioral Sciences, Jimma University Specialized Hospital and Psychiatry Department in Ethiopia. We appreciate the valuable contributions from the data collectors, data entry clerks, supervisors, and respondents. We forward our sincere thanks to the $\mathrm{CIH}^{\mathrm{LMU}}$ Center for International Health, Ludwig-Maximilians-Universität, Munich, Germany, and its funding agencies, the German Academic Exchange Service (DAAD), the DAAD-Exceed Program, and the German Ministry for Economic Cooperation and Development for their support. This study was supported by the Köhler foundation. Thanks to Danielle Schaub for editing the manuscript.

\section{Author contributions}

Eshetu Girma, Markos Tesfaye, and Sandra Dehning designed the study, and were involved in the data collection, analysis, and drafting of the manuscript. Guenter Froeschl, Anne Maria Möller-Leimkühler, and Norbert Mueller were involved in the design of the study, analysis of the data, and critically reviewed the manuscript. All authors read and approved the final manuscript.

\section{Disclosure}

The authors declare no conflicts of interest in this work.

\section{References}

1. Panayiotopoulos C, Pavlakis A, Apostolou M. Family burden of schizophrenic patients and the welfare system; the case of Cyprus. Int J Ment Health Syst. 2013;7(1):13. 
2. Larson JE, Corrigan P. The stigma of families with mental illness. Acad Psychiatry. 2008;32(2):87-91.

3. Tessler R, Gamache G. Evaluating Family Experiences with Severe Mental Illness. Cambridge, MA: Human Services Research Institute; 1993.

4. Holden DF, Lewine RR. How families evaluate mental health professionals, resources, and effects of illness. Schizophr Bull. 1982;8(4): 626-633.

5. Ohaeri JU. Caregiver burden and psychotic patients' perception of social support in a Nigerian setting. Soc Psychiatry Psychiatr Epidemiol. 2001;36(2):86-93.

6. Schene AH, van Wijngaarden B, Koeter MW. Family caregiving in schizophrenia: domains and distress. Schizophr Bull. 1998;24(4): 609-618.

7. Magliano L, Marasco C, Fiorillo A, Malangone C, Guarneri M, Maj M; Working Group of the Italian National Study on Families of Persons with Schizophrenia. The impact of professional and social network support on the burden of families of patients with schizophrenia in Italy. Acta Psychiatr Scand. 2002;106(4):291-298.

8. Perlick DA, Rosenheck RA, Kaczynski R, Swartz MS, Cañive JM, Lieberman JA. Components and correlates of family burden in schizophrenia. Psychiatr Serv. 2006;57(8):1117-1125.

9. Corrigan PW, Watson AC, Miller FE. Blame, shame, and contamination: the impact of mental illness and drug dependence stigma on family members. J Fam Psychol. 2006;20(2):239-246.

10. Tanaka G, Ogawa T, Inadomi H, Kikuchi Y, Ohta Y. Effects of an educational program on public attitudes towards mental illness. Psychiatry Clin Neurosci. 2003;57(6):595-602.

11. Chang KH, Horrocks S. Lived experiences of family caregivers of mentally ill relatives. J Adv Nurs. 2006;53(4):435-443.

12. Van Brakel WH. Measuring health-related stigma - a literature review. Psychol Health Med. 2006;11(3):307-334.

13. Corrigan P. How stigma interferes with mental health care. Am Psychol. 2004;59(7):614-625.

14. Phillips MR, Pearson V, Li F, Xu M, Yang L. Stigma and expressed emotion: a study of people with schizophrenia and their family members in China. Br J Psychiatry. 2002;181:488-493.

15. Angermeyer MC, Schulze B, Dietrich S. Courtesy stigma - a focus group study of relatives of schizophrenia patients. Soc Psychiatry Psychiatr Epidemiol. 2003;38(10):593-602.
16. Struening EL, Perlick DA, Link BG, Hellman F, Herman D, Sirey JA. Stigma as a barrier to recovery: The extent to which caregivers believe most people devalue consumers and their families. Psychiatr Serv. 2001;52(12):1633-1638.

17. Kadri N, Manoudi F, Berrada S, Moussaoui D. Stigma impact on Moroccan families of patients with schizophrenia. Can J Psychiatry. 2004;49(9):625-629.

18. Ciftci A, Jones N, Corrigan PW. Mental health stigma in the Muslim community. Journal of Muslim Mental Health. 2012;7(1):17-32.

19. Corrigan PW. Best practices: Strategic stigma change (SSC): five principles for social marketing campaigns to reduce stigma. Psychiatr Serv. 2011;62(8):824-826.

20. Goffman E. Stigma. Notes on the Management of Spoiled Identity. Simon \& Shuster: New York, NY; 1963

21. Hebl MR, Mannix LM. The weight of obesity in evaluating others: a mere proximity effect. Pers Soc Psychol Bull. 2003;29(1):28-38.

22. Deribew A, Tamirat YS. How are mental health problems perceived by a community in Agaro town? Ethiop J Health Dev. 2005;19(2):153-159.

23. Girma E, Tesfaye M. Patterns of treatment seeking behavior for mental illnesses in Southwest Ethiopia: a hospital based study. BMC Psychiatry. 2011;11:138.

24. Bekele YY, Flisher AJ, Alem A, Baheretebeb Y. Pathways to psychiatric care in Ethiopia. Psychol Med. 2009;39(3):475-483.

25. Shibre T, Negash A, Kullgren G, et al. Perception of stigma among family members of individuals with schizophrenia and major affective disorders in rural Ethiopia. Soc Psychiatry Psychiatr Epidemiol. 2001;36(6):299-303.

26. Mak W, Cheung R. Affiliate Stigma Among Caregivers of People with Intellectual Disability or Mental Illness. $J$ Appl Res Intellect Disabil. 2008;21(6):532-545.

27. Sartorius N, Janca A. Psychiatric assessment instruments developed by the World Health Organization. Soc Psychiatry Psychiatr Epidemiol. 1996;31(2):55-69.

28. Corrigan PW. Target-specific stigma change: a strategy for impacting mental illness stigma. Psychiatr Rehabil J. 2004;28(2):113-121.

29. Corrigan PW, Penn DL. Lessons from social psychology on discrediting psychiatric stigma. Am Psychol. 1999;54(9):765-776.

30. Yee JL, Schulz R. Gender differences in psychiatric morbidity among family caregivers: a review and analysis. Gerontologist. 2000;40(2): $147-164$.
Journal of Multidisciplinary Healthcare

\section{Publish your work in this journal}

The Journal of Multidisciplinary Healthcare is an international, peerreviewed open-access journal that aims to represent and publish research in healthcare areas delivered by practitioners of different disciplines. This includes studies and reviews conducted by multidisciplinary teams as well as research which evaluates the results or conduct of such teams or

\section{Dovepress}

healthcare processes in general. The journal covers a wide range of areas and welcomes submission from practitioners at all levels, from all over the world. The manuscript management system is completely online and includes a very quick and fair peer-review system. Visit http://www.dovepress.com/testimonials.php to read real quotes from published authors. 